\title{
Responsabilidade social: o investimento social de micro e pequenas empresas do Programa de Desenvolvimento de Empresas e Organizações Sociais (PDEOS), da Fundação Dom Cabral — Brasil
}

\author{
Helena Maria Gomes Queiroz* \\ Michelle Queiroz Coelho**
}

Brasil

\section{Resumo}

Este artigo tem o objetivo de analisar o investimento social das empresas participantes do pDEos. Para isso, foi feito um estudo de caso na Rede PDEOS, que consistiu em uma pesquisa do tipo exploratória e descritiva, com abordagem qualitativa. Foram avaliadas as parcerias desenvolvidas, que já somam mais de 340 nos quatro primeiros anos de atuação.

Palavras-chave: Investimento Social. Micro e Pequenas Empresas. Responsabilidade Social.

\section{Introdução}

A Fundação Dom Cabral (FDC) criou, em 2008, o Jardim de Oportunidades, um conjunto de projetos estruturantes do Jardim Canadá,

* Doutora em Educação. Mestre em Administração. Fundação Dom Cabral. helenatrilha@gmail.com

** Mestre em Administração. Fundação Dom Cabral. michelletrilha@gmail.com 
que iniciou com um diagnóstico sobre a região e, a partir dos resultados obtidos, surgiram diversos projetos de desenvolvimento local sustentável. Entre eles, o Programa de Desenvolvimento de Empresas e Organizações Sociais (PDEOS), que tem como objetivo estimular o desenvolvimento local sustentável a partir da promoção da gestão responsável junto às lideranças empresariais e comunitárias do Bairro Jardim Canadá e região. No PDEOs, a FDC atua em três eixos:

- sensibiliza as lideranças empresariais sobre o desenvolvimento local sustentável a partir do entendimento do tema e das potenciais contribuições de seu negócio;

- contribui para ampliar o conhecimento e a prática da gestão responsável no contexto das organizações sociais;

- promove a articulação entre empresas e organizações sociais participantes.

O primeiro ciclo do PDEOS iniciou-se em 2012, com a presença de seis empresas de pequeno e médio porte e seis organizações sociais, todas sediadas no Jardim Canadá. No segundo ano do programa, em 2013, mais seis empresas e seis organizações sociais foram convidadas a participar. Com o programa já no terceiro ano, em 2014, quatro empresas e quatro organizações passaram a integrar o grupo. Finalmente, em 2015, em seu quarto ciclo, foram selecionadas mais quatro empresas e duas organizações sociais.

Durante essa trajetória de quase cinco anos, o trabalho desenvolvido foi concentrado no Jardim Canadá porque é a região de entorno na qual o principal campus da Fundação Dom Cabral está inserido e por isso o desejo de estabelecer vínculos fortes de apoio ao desenvolvimento da comunidade local.

A diferença básica em relação ao formato de atuação nos quatro ciclos é a periodicidade das monitorias, que começam com quinzenais para organizações sociais e mensais para empresas - ambas do primeiro ciclo - e chegam a semestrais, no quarto ciclo. Isso porque o programa parte do pressuposto que, com o passar dos anos, os integrantes da Rede sentem-se mais seguros em relação às práticas gerenciais desenvolvidas e ao diálogo mais direto nas relações de parceria. 
Nesse contexto, este artigo tem o objetivo de analisar o investimento social das empresas participantes do PDEos. Para isso, foi feito um estudo de caso na Rede PDEOS, que consistiu em uma pesquisa do tipo exploratória e descritiva, com abordagem qualitativa. Foram avaliadas as parcerias desenvolvidas, que já somam mais de 340 nos quatro primeiros anos de atuação. O recorte do artigo é para as iniciativas desenvolvidas entre empresas e organizações sociais em duas categorias centrais: recursos financeiros e recursos diversos. As doações de recursos financeiros foram analisadas, sendo a maioria delas, doações regulares geralmente como recurso livre, ou seja, a organização social determina a prioridade de utilização do recurso.

Apresentamos, ainda, outros formatos de recursos financeiros como aqueles vinculados à compra de produtos gerados pelas organizações sociais, além de um formato mais recente, que são as doações financeiras atreladas a campanhas de Marketing para Causas Sociais. Esse é um dos dados mais interessantes da avaliação, pois demonstra, sobretudo na realidade das micro e pequenas empresas, que é possível contribuir para o desenvolvimento local, independente do porte e dos recursos financeiros disponíveis.

\section{Marco teórico}

O marco teórico apresenta o conceito de "Responsabilidade Social" que a Iso 26000 aborda: a responsabilidade social de micro e pequenas empresas, o investimento social privado e as particularidades das micro e pequenas empresas nesse contexto. Por fim, apresenta-se abordagem de autores sobre Redes e Parcerias.

\section{Responsabilidade social: conceito da iso 26000}

Antes de apresentar a metodologia de construção do Programa de Investimento Social (PIS), é importante apresentar o conceito de "Responsabilidade Social”, especificada na Iso 26 000. Lançada em 2010, a ISO 26000 estabelece um padrão internacional de diretrizes de Responsabilidade Social. O Brasil, representado pela Associação Brasileira 
de Normas Técnicas (ABNT), em conjunto com o Swedish Standard Institute (SIS), da Suécia, foram responsáveis pela condução dos trabalhos, liderando o Grupo de Trabalho (ISO/TMB WG - WorkingGroup) de Responsabilidade Social da ISO (com mais de 430 pessoas de 72 países e 35 organizações internacionais).

Para a norma, a responsabilidade social é definida como "a responsabilidade de uma organização pelos impactos de suas decisões e atividades na sociedade e no meio ambiente, por meio de um comportamento ético e transparente que contribua para o desenvolvimento sustentável, inclusive a saúde e o bem-estar da sociedade; leve em consideração as expectativas das partes interessadas; esteja em conformidade com a legislação aplicável; seja consistente com as normas internacionais de comportamento e esteja integrada em toda a organização e seja praticada em suas relações" (ISO 26 000, 2010).

1. A norma apresenta sete temas centrais, a saber:

2. Governança Organizacional

3. Direitos Humanos

4. Práticas Leais de Trabalho

5. Meio Ambiente

6. Práticas Leais de Operação

7. Questões Relativas ao Consumidor

8. Envolvimento e Desenvolvimento da Comunidade

Apesar da capilaridade da atuação do PDEOS, o programa atua prioritariamente no tema 7, Envolvimento e Desenvolvimento da Comunidade. Esse tema apresenta sete questões possíveis de serem abordadas pelas organizações, a saber:

1. Envolvimento da comunidade

2. Educação e cultura

3. Geração de emprego e capacitação

4. Desenvolvimento tecnológico e acesso às tecnologias

5. Geração de riqueza e renda

6. Saúde

7. Investimento social 
Ainda considerando a Iso 26000 como referência, o desenvolvimento da comunidade, de uma maneira ampla, envolve a melhoria na qualidade de vida de uma população. No entanto, é preciso reconhecer que não se trata de um processo linear e as partes interessadas podem ter motivações diferentes, até mesmo conflitantes. O envolvimento de uma empresa com a comunidade deve, portanto, partir da premissa de que é possível encontrar interesses comuns, apesar das diferenças. $\mathrm{O}$ compartilhamento de responsabilidades é necessário para a promoção do bem-estar da comunidade como um objetivo coletivo.

Ainda de acordo com a norma, os investimentos sociais podem contribuir para o desenvolvimento, fortalecendo o relacionamento de uma empresa com a comunidade. Esse investimento pode, ou não, estar associado às principais atividades da empresa.

Finalmente, a norma destaca que o envolvimento da comunidade é uma forma proativa de a empresa participar da comunidade ao estabelecer parcerias com organizações, participação de Redes, entre outros. É justamente nesse contexto que o PDEOS atua.

\section{Responsabilidade social de micro e pequenas empresas}

A responsabilidade social não é apenas uma questão de grandes empresas. Seabra (2015) ressalta que pequenas empresas estão também vinculadas a princípios e valores éticos. Para o autor, cada empresa deve proceder aos seus próprios diagnósticos de situação e repensar a sua atuação.

Práticas responsáveis em pequenas e médias empresas são possíveis. Entretanto, Vives (2011) salienta que há que se ter cuidado em não as comparar com as ações de grandes empresas. As razões e motivações são diferentes. Elas enfrentam menos pressão das partes interessadas, dependem mais das motivações dos donos, gerentes e empregados. As pequenas empresas estão menos conscientes dos benefícios potenciais das práticas responsáveis, têm menos recursos, tanto financeiros, quanto humanos. O autor complementa dizendo que as associações empresariais devem implementar programas para promover essas práticas e os governos devem estimular sua adoção. 
Para Alesandria e Gesualdo (2013), o conhecimento sobre a aplicação da responsabilidade social empresarial nas pequenas e médias empresas permite iniciar um processo de retroalimentação e transferência, o que contribui para soluções adaptadas às suas características específicas e resulta em uma vantagem competitiva que gera valor econômico, social e ambiental, e isso favorece o desenvolvimento sustentável do entorno.

Diversas são as formas nas quais a Responsabilidade Social Empresarial (RSE) pode favorecer a competitividade das MPEs, de acordo com Durán (2013):

- melhora dos produtos e processos que se traduzem em maior satisfação e lealdade do cliente;

- maior motivação e fidelidade dos trabalhadores, aumentando sua criatividade e inovação;

- melhor imagem pública, devido a prêmios ou um maior reconhecimento pela sociedade;

- melhor posição no mercado de trabalho;

- aplicação de padrões internacionais de gestão social e ambiental que permite o acesso a mercados internacionais;

- melhor relação com outros agentes empresariais e autoridades;

- melhora da rentabilidade devido à maior eficiência do uso dos recursos; e

- aumento das vendas como consequência do supracitado.

As MPEs precisam apresentar ações mais efetivas na busca da satisfação dos colaboradores envolvidos com o negócio, bem como dos interesses da comunidade e apoio às ações que visem preservar o meio ambiente. Também se enfatiza a necessidade de o Estado estar mais presente e dar um apoio intensivo a empresas desse porte. Em pesquisa realizada com 126 microempresas em um Município do Rio de Janeiro, Khalil (2005) menciona alguns dos resultados encontrados. Há uma fragilidade dos empresários em definir as ações de responsabilidade social que praticam em suas empresas como ações concretas. Para eles, essas ações são inerentes somente às grandes empresas. Eles consideram que suas ações sociais são práticas individuais de melhoria 
das relações com seus funcionários e com a comunidade na qual atuam, o que caracteriza filantropia e não responsabilidade social. Essas práticas são de humanidade e bom senso.

\section{Investimento social privado e as micro e pequenas empresas}

Este artigo dedica-se a compreender melhor o conceito de "Investimento Social Privado" e alguns dados sobre esse mercado com atenção ao contexto das micro e pequenas empresas, foco do PDEOS.

De acordo com Deboni (2013), o conceito foi criado nos anos 1990 pelos líderes que deram origem ao Grupo de Institutos e Fundações Empresariais (Gife), que buscava diferenciar a atuação social das empresas e fundações privadas da forma tradicional de filantropia, predominantemente assistencialista.

Para o grupo, "Investimento Social Privado" é o repasse voluntário de recursos privados de forma planejada, monitorada e sistemática para projetos sociais, ambientais e culturais de interesse público. Incluem-se nesse universo as ações sociais protagonizadas por empresas, fundações e institutos de origem empresarial ou instituídos por famílias, comunidades ou indivíduos (Gife, 2015).

Já para o Instituto para o Desenvolvimento do Investimento Social (Idis), "Investimento Social" é a alocação voluntária e estratégica de recursos privados, sejam eles financeiros, em espécie, humanos, técnicos ou gerenciais, para o benefício público (Idis, 2015). Esse conceito é o que adotamos dentro do PDEOS pela importância que as parcerias com recursos diversos (não-financeiros) representam em nossos resultados.

Apresentamos alguns dados interessantes do Benchmarking do Investimento Social Corporativo (BISC), que faz um acompanhamento anual dos investimentos sociais privados no Brasil. Foi criado em 2008 pela Comunitas, uma organização da sociedade civil que tem a missão de contribuir para o aprimoramento dos investimentos sociais corporativos.

Em sua edição de 2014, o relatório traz resultados obtidos a partir de pesquisa com mais de 300 empresas, fundações e institutos que operam no Brasil. Os dados revelam que o investimento foi da ordem de 
dois bilhões de reais em 2013. Mesmo sendo inferior ao ano anterior, ainda assim pode ser considerado positivo tendo em vista a conjuntura econômica do país. Além disso, a participação dos investimentos sociais no lucro das empresas manteve-se bem acima do padrão internacional apresentado pelo CECP, instituição parceira da Comunitas (BISC, 2015).

A pesquisa do Instituto de Pesquisa Econômica Aplicada (Ipea) de 2006, apesar de mais antiga, representa o último estudo do Instituto e indicou que cerca de $60 \%$ das empresas brasileiras têm alguma atuação social, com investimentos da ordem de $\mathrm{R} \$ 6$ bilhões (dado atualizado pela inflação para 2009). A pesquisa destaca que uma quantidade significativa de Micro e Pequenas Empresas (MPEs) relatam ações sociais - nas empresas de 1 a 10 empregados, $66 \%$ delas contribuem (Ipea, 2015) - .

O potencial de crescimento da atuação social nas Micro e Pequenas Empresas é enorme. Alguns dos dados apontados na pesquisa divulgada pelo Serviço Brasileiro de Apoio a Pequenas e Médias Empresas (Sebrae), em 2014, ilustram esse contexto:

- as MPEs geraram, em 2011, $27 \%$ do valor adicionado do conjunto de atividades pesquisadas (РІB). Esse percentual vem aumentando na série histórica, iniciada em 1985, quando esse indicador representava $21 \%$ do valor adicionado (PIB), e em 2001, 23,2 \%;

- em relação ao número de empresas, as MPEs representaram, em 2011, nas atividades de serviços e de comércio, respectivamente, $98 \%$ e $99 \%$ do total de empresas formalizadas;

- em relação ao emprego, as MPEs representavam $44 \%$ dos empregos formais em serviços e, aproximadamente, $70 \%$ dos empregos gerados no comércio.

Muitas vezes, as organizações sociais não abordam esse perfil de empresa, pois acreditam que a chance de obter recursos é menor e, mesmo que consigam os valores podem não ser expressivos como obviamente uma grande empresa teria condições de investir. No entanto, as possibilidades são inúmeras em função do grande volume de empresas e benefícios, como a diversificação dos recursos. 
As empresas têm ensaiado múltiplas formas de interação com as Organizações Não Governamentais (ONGs). O resultado de pesquisas demonstra que é formado um circuito virtuoso do trabalho em aliança pelo qual as empresas tendem a integrar parcerias com ONGs reconhecidas em suas atividades, o que gera expectativas favoráveis com sua atuação. Se os resultados das ações são satisfatórios, a consequência é a credibilidade da aliança, a qual gera seu fortalecimento, conforme ressalta Gorrochategui e Oliveira (2015).

\section{Redes e parcerias}

Acreditamos ser relevante contextualizar o conceito de "Rede" pela importância que representa no PDEOS. As referências são variadas, mas Inojosa (1999) traz uma reflexão interessante sobre as redes de compromisso social, contexto no qual o PDEOs se enquadra. Elas são definidas com um tipo específico de rede que têm como foco questões sociais e que visam complementar a ação do Estado ou suprir a sua ausência no equacionamento de problemas sociais complexos. A autora destaca ainda que as relações nascem e se nutrem de uma visão comum sobre a sociedade ou sobre determinada questão social.

Em especial as alianças em rede entre empresas e as organizações da sociedade civil, um dos focos principais do PDEOS, combinam competências, infraestruturas, conhecimentos e esferas de influência de seus respectivos setores, além de contribuir para a geração de inovação social de um modo mais eficaz do que a atuação isolada de qualquer das partes, de acordo com Lariú e Berendson (2008). Cada setor apresenta competências, aspirações e estilos diferentes, mas, de acordo com os autores, é possível juntá-los e obter uma visão comum.

O conceito de "parceria" que adotamos no pDEos foi adaptado a partir de Hiernaux (1997), e é definido como a relação entre atores em torno da descoberta de interesses comuns articuláveis. Para o autor, a existência de interesses comuns é considerada um dos elementos-chave cuja articulação é traduzida na utilização conjunta de recursos disponibilizados (financeiros, humanos, físicos, entre outros).

A gestão de políticas públicas e projetos sociais, de acordo com Teodósio (2009), passou por transformações e incorporou o discurso 
da construção de parcerias como um elemento central e essencial para sua efetivação. As organizações da sociedade civil e, mais recentemente, também as empresas, tiveram um papel relevante nessa dinâmica. Paralelamente às discussões sobre as condições para a concretização de políticas e projetos sociais mais efetivos e eficientes, atores de Estado, empresas e organizações da sociedade civil têm sido levados a repensar e reordenar seus papéis na sociedade contemporânea. Interações entre atores de Estado, organizações da sociedade civil e empresas adquiriram lugar de destaque nas discussões acadêmicas e na formulação de agendas de políticas sociais a partir das últimas décadas, conforme aponta o autor.

Em especial, as empresas buscam fazer alianças, porque as experiências em conjunto têm se mostrado mais eficazes do que as individuais, de acordo com Fischer (1998). Oded Grajew, do Instituto Ethos de Responsabilidade Social, reforça essa importância quando diz que os projetos sociais precisam de recursos financeiros, econômicos, culturais, tecnológicos e humanos. "De forma isolada, essas possibilidades são limitadas, mas na forma de parcerias é possível juntar forças para reduzir as mazelas da população brasileira” (Ethos, 2015).

O Instituto Ethos conta com mais de 1.000 associados, com empresas dos mais diversos portes e segmentos produtivos. Somadas, representam em torno de $35 \%$ do PIB brasileiro e empregam aproximadamente dois milhões de pessoas. Entre essas 1.000 empresas associadas, de acordo com Meiriño (2012, p. 142), 20,92 \% são microempresas e $27,71 \%$ são pequenas empresas.

Para estabelecer parcerias satisfatórias para as partes envolvidas, vários aspectos são necessários. O quadro a seguir apresenta os "Sete Cs da boa parceria", adaptados a partir de Austin (2000): 


\section{Quadro 1. Sete Cs da boa parceria}

\begin{tabular}{|c|c|c|}
\hline $7 \mathrm{Cs}$ & $\begin{array}{l}\text { Aspectos da re- } \\
\text { lação de parceria }\end{array}$ & Questões importantes da parceria \\
\hline 1. & $\begin{array}{l}\text { Clareza de pro- } \\
\text { pósito }\end{array}$ & $\begin{array}{l}\text { Os parceiros têm clareza do propósito da colabo- } \\
\text { ração? } \\
\text { Em que estágio de colaboração a relação se encaixa e } \\
\text { qual é o desejo dos participantes? }\end{array}$ \\
\hline 2. & Compromisso & $\begin{array}{l}\text { Qual é o nível de compromisso da organização com a } \\
\text { parceria e como é demonstrado? } \\
\text { Qual é o tipo de investimento feito na parceria pes- } \\
\text { soal, humana, financeira? } \\
\text { O conjunto de parcerias é compatível com a capacida- } \\
\text { de de colaboração de cada envolvido? }\end{array}$ \\
\hline 3. & Conexão & $\begin{array}{l}\text { Os indivíduos estão conectados/ envolvidos com os } \\
\text { propósitos da colaboração? } \\
\text { Qual é o nível e qualidade da interação? } \\
\text { Há interação entre todos os níveis nas organizações } \\
\text { parceiras? }\end{array}$ \\
\hline 4. & Congruência & $\begin{array}{l}\text { Os parceiros conhecem missão, objetivos, estratégias e } \\
\text { valores do outro? } \\
\text { Há sobreposição? } \\
\text { Como podem ajudar o outro a alcançar a sua missão? } \\
\text { Os parceiros compartilham uma visão de futuro? }\end{array}$ \\
\hline 5. & Criação de valor & $\begin{array}{l}\text { Qual é a relação custo-benefício da parceria? } \\
\text { Existem benefícios para ambos os lados? }\end{array}$ \\
\hline 6. & Comunicação & $\begin{array}{l}\text { Há respeito e confiança entre as partes? } \\
\text { A comunicação interna e externa é aberta, franca e } \\
\text { construtiva? } \\
\text { Como a comunicação é gerenciada? } \\
\text { Há dissidentes? Como poderiam ser convencidos? }\end{array}$ \\
\hline 7. & $\begin{array}{l}\text { Contínuo apren- } \\
\text { dizado }\end{array}$ & $\begin{array}{l}\text { O que tem sido aprendido pelas partes? } \\
\text { O aprendizado tem sido incorporado na colaboração? } \\
\text { O aprendizado é avaliado? }\end{array}$ \\
\hline
\end{tabular}

Fonte: adaptado de Austin (2000).

Woods (2015) destaca que as parcerias com investidores sociais podem representar diversos ganhos para as organizações, muito além da contribuição financeira. Nas boas práticas de Investimento Social 
Privado no Brasil, vemos que essas parcerias também envolvem algumas das características a seguir.

- Ferramentas de gestão: é comum serem oferecidas capacitações e instrumentos de gestão em diversos temas, como elaboração e avaliação de projetos, planejamento estratégico, comunicação e captação de recursos. A premissa para esses investimentos é de que, ao melhorar seu gerenciamento, as organizações melhoram sua performance e, consequentemente, os serviços entregues ao beneficiário final e sua contribuição para a causa.

- Troca de experiências e aprendizados: os investidores sociais podem proporcionar espaços de troca, articulação e atuação em rede entre os projetos e organizações apoiados dentro de um mesmo foco de atuação. A premissa é a mesma do item anterior - fortalecer a atuação das organizações parceiras.

- Visibilidade e credibilidade: o apoio de um investidor social acaba sendo uma chancela que confere credibilidade à organização e ao projeto apoiado. Muitos deles também investem na divulgação da parceria e dos resultados da iniciativa conjunta, o que pode contribuir para o fortalecimento da imagem institucional da organização.

Todas as boas práticas citadas estão intrinsecamente ligadas à proposta da FDC ao criar o PDEOS como uma de suas principais estratégias de investimento social.

Recuperando o conceito já apresentado pelo Idis, "Investimento Social" é a alocação voluntária e estratégica de recursos privados, sejam eles financeiros, em espécie, humanos, técnicos ou gerenciais, para o benefício público. Percebemos que os recursos vão muito além da dimensão financeira (Idis, 2015).

Para ilustrar melhor esse conceito, apresentamos no próximo tópico alguns resultados de parcerias da Rede PDEOs envolvendo não apenas recursos financeiros, mas também recursos humanos, recursos físicos, serviços e produtos. 


\section{Metodologia e resultados}

Para elaborar este artigo foi utilizada uma metodologia de pesquisa do tipo exploratória e descritiva, com abordagem qualitativa. Um estudo de caso foi realizado com as empresas participantes da Rede PDEos, no Jardim Canadá, município de Nova Lima, no Estado de Minas Gerais, no Brasil. Foram analisados relatórios mensais com os resultados das parcerias realizadas pelas 20 empresas constantes da Rede PDEOS, no período de 2012 a 2015. Por uma questão de sigilo, o nome da empresa e das organizações sociais participantes não são citados.

Um dos principais resultados do PDEOs são as parcerias realizadas entre os participantes da Rede. O Gráfico 1, a seguir, ilustra bem essa evolução do Programa ao longo dos anos.

Gráfico 1. Evolução de parcerias

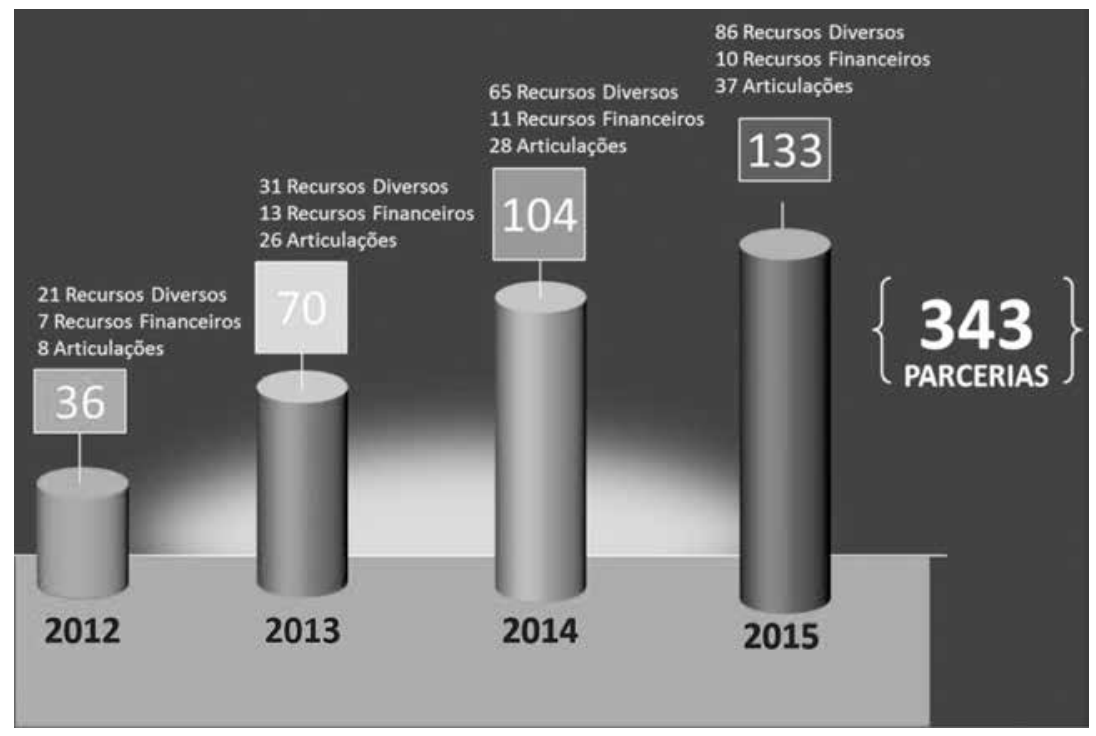

Fonte: Fundação Dom Cabral (2015).

Destacamos a seguir uma avaliação de exemplos das parcerias realizadas nas categorias "Recursos Diversos" e "Recursos Financeiros", que são os conjuntos que envolvem diretamente as pequenas e microempresas, foco do presente artigo. 


\section{Recursos financeiros}

Nesta categoria estão incluídas todas as doações de recursos financeiros. A maioria delas são doações regulares geralmente como recurso livre, ou seja, a organização social determina a prioridade de utilização do recurso. Um dos exemplos é a parceria realizada em 2013 entre uma pequena empresa e uma organização social, no valor de R \$ 60.000,00. A assinatura do Contrato de Parceria entre as partes foi feita na FDC.

Outros formatos de recursos financeiros são aqueles vinculados à compra de produtos gerados pelas organizações sociais. A própria empresa citada comprou brindes da organização social para entregar a diversos públicos de relação. Vale ressaltar que todos os tecidos utilizados na produção dos brindes são doados por outra empresa integrante da Rede PDEOS.

Um último formato mais recente é o das doações financeiras atreladas às campanhas de Marketing para Causas Sociais. Um ótimo exemplo é a parceria realizada, em 2015, entre uma organização social e um restaurante da Rede PDEOS. O restaurante ofereceu duas opções de menu com entrada, prato principal e sobremesa ao preço fixo de $\mathrm{R} \$ 60,00$. De cada menu consumido, $\mathrm{R} \$ 10,00$ foram doados para o projeto.

\section{Recursos diversos}

Esta categoria está segmentada em dois tipos de parcerias. O primeiro entre as próprias organizações sociais e, o segundo tipo entre empresas e organizações sociais, sendo, este último, o foco do presente estudo. Os recursos diversos podem ser humanos, físicos, produtos ou serviços, conforme destacado a seguir.

\section{Recursos humanos}

Muitas empresas têm envolvido seu público interno, desde diretores até a equipe operacional, em ações voluntárias em prol das organizações sociais. Um exemplo interessante é a parceria entre uma empresa e a Escola Municipal. A escola precisava criar um espaço de leitura para os alunos e a empresa cedeu, então, um contêiner. A Gerência de Pessoas organizou um "Dia V" englobando vários funcionários na produção de acordo com o projeto solicitado pela escola. O circuito social 
promoveu ações de integração que incluíram visitas da empresa à escola e de crianças da escola à empresa.

\section{Recursos físicos}

Neste tipo de parceria a empresa cede recursos físicos para as organizações sociais. Duas parcerias interessantes para ilustrar essa categoria foram desenvolvidas por uma empresa de eventos, que cedeu a casa de festas e o mobiliário completo para eventos realizados com a Escola Estadual e com a Escola Municipal.

A formatura em destaque é um ótimo exemplo para ilustrar que um mesmo acontecimento pode catalisar diversas parcerias em diferentes categorias. Além do espaço cedido, tivemos parcerias de mais três organizações: apresentação cultural, apoio de equipamentos e produção do evento.

\section{Produtos}

Nesta categoria a empresa doa produtos às organizações sociais parceiras em duas modalidades: doações diretas e/ou doações de clientes. Um exemplo dessa dupla abordagem são as várias campanhas desenvolvidas pelas lojas de roupa em benefício de duas organizações sociais. A empresa não só doa diretamente as roupas, como também estimula as doações de seus clientes através de campanhas diversas, concedendo inclusive descontos. Esse também é um exemplo do ativismo corporativo, mencionado anteriormente neste artigo.

\section{Serviços}

Nesta categoria a empresa oferece serviços gratuitos para as organizações sociais. Um dos exemplos são os cursos e oficinas sobre reciclagem de embalagens longa vida realizados por uma empresa para uma organização social e a Escola Municipal. A prestação de serviço ainda tem como resultado a geração de produtos, como as cortinas utilizadas pelas organizações em suas respectivas sedes.

\section{Novas Perspectivas de Resultados}

Além dos exemplos mencionados, apresentamos um mini case com um exemplo de parceria entre empresa e organização social, destacando 
novas perspectivas de resultados, como a capacidade de engajamento dos públicos de interesse.

\section{Os envolvidos}

Organização Social: membro da Rede PDEOS desde 2014, a organização tem como missão contribuir para a difusão e consolidação de práticas e princípios éticos que orientem o ser humano para uma interação cooperativa $\mathrm{e}$ harmoniosa entre si e com os processos da natureza, por meio das atividades de pesquisa, educação e desenvolvimento de projetos socioambientais.

Empresa: membro da Rede PDEOS desde 2015, a empresa fundada há 18 anos atua no segmento de ciclismo e oferecendo a bicicleta, as peças, os acessórios e vestuário, afim de satisfazer as necessidades e proporcionar a melhor experiência possível quando se está pedalando.

\section{A prática envolvida}

A parceria com a organização social envolveu diversos atores da rede de relacionamento. Entre eles, destacamos o seguinte.

Empresa: doou bicicleta e bicicletário, com contrapartida de um estudo para gestão de resíduos.

Projeto Baldinhos Leva e Traz: envolvimento da comunidade do Vale do Sol na compostagem.

Parceiros Rede PDEOs: identidade visual do baldinho; comunicação e design.

Parceiros externos: ecodesigner e arquiteto que desenvolveram o suporte em bambu e sisal para carregar os baldinhos na bicicleta e estrutura em bambu para cobrir a composteira.

\section{Principais resultados}

Destacaremos alguns resultados sob a perspectiva quantitativa e qualitativa (através de depoimentos dos diversos envolvidos).

- Seis stakeholders envolvidos

- Vale do Sol:

- Vizinhos que participam da ação: 14

- Crianças e jovens que participam da ação: 17

- Total: 31 
- Quantidade de resíduos: aproximadamente 200 a 250 kg por mês

\section{Para a Coordenadora de Projetos da organização social}

[...] é muito gratificante ver projetos que começam como sonhos e se tornam realidade. O sonho maior que se constrói gradativamente é o fortalecimento de uma comunidade de pessoas, empresas e organizações que se unem, cooperam, confiam e creem que de mãos dadas é possível irmos mais longe, rumo a um mundo mais justo e solidário.

A responsável pelo departamento administrativo da organização social destaca que as parcerias em geral, no atual cenário financeiro do país, "têm papel fundamental para dar andamento em projetos e sonhos de organizações sociais [...]. Agradecemos imensamente a todos nossos parceiros que acreditam no nosso trabalho e fazem parte do nosso sonho".

O ecodesigner parceiro destacou a importância do ecodesign em projetos como esses. O pneu é um enorme problema ambiental e "dar nova vida a ele é um desafio. Além disso, a adaptação da carretinha para recolhimento dos resíduos com a bicicleta também traz um resultado muito positivo. Parabéns a todos os envolvidos nesta parceria".

A diretora da empresa reforçou que

[...] a parceria através do PDEOS foi uma experiência maravilhosa pelo simples prazer em contribuir e interessante por sabermos o direcionamento das doações, seus impactos e os resultados obtidos. Em especial o trabalho da organização social nos chamou a atenção, pois acabou envolvendo tanta gente a partir da doação da bicicleta, além da própria contrapartida da gestão de resíduos. Os resultados me deixam honrada e feliz. Uma bicicleta fazer tanto movimento pode mesmo contribuir para fazer o mundo girar, o primeiro slogan da empresa. 
Como podemos observar através desse exemplo, as parcerias desenvolvidas pelo Programa trazem um potencial enorme de resultado envolvendo diversos públicos de relacionamento: a comunidade, o meio ambiente, clientes, fornecedores, parceiros, governo, entre outros.

\section{Considerações finais}

Algumas lições interessantes podem ser extraídas da experiência do PDEOS em seus quatro anos de atuação. Em primeiro lugar, a eficácia do trabalho em rede, quando precedido da formação responsável de lideranças empresariais e comunitárias.

Em segundo lugar, o valor, para além da dimensão financeira, que as várias parcerias desenvolvidas entre os participantes foram capazes de mobilizar. Um reflexo disso é o maior volume de parcerias que vem da categoria "recursos diversos", o que demonstra, sobretudo na realidade das micro e pequenas empresas, que é possível contribuir para o desenvolvimento local, independentemente do porte e dos recursos financeiros disponíveis.

Como toda pesquisa, o presente estudo apresenta limitações relacionadas ao recorte metodológico, como, por exemplo, ressaltar os resultados apenas das empresas envolvidas, além do próprio limite geográfico que destaca a atuação em uma região específica de Nova Lima.

Assim, sugerimos o desenvolvimento de novas pesquisas no sentido de explorar diferentes dimensões de resultados envolvendo as organizações sociais, além da comparação de impacto em novos territórios de atuação.

Finalmente, esperamos ter contribuído para uma melhor compreensão do Programa e, sobretudo, acreditamos no potencial de incentivar a multiplicação dessa iniciativa em outras realidades, o que favorece a constituição de uma nova tecnologia social de articulação em rede capaz de contribuir significativamente para o desenvolvimento da sociedade. 


\section{Referências}

Alesandria, H. \& Gesualdo, G. K. (2013) Puede la responsabilidad social empresarial incrementar la competitividad de las PYMEs? Em N. Gorrochategui, V. M. Oliveira \& O. D. Licandro (comps.), Responsabilidad social de las organizaciones (RSO): panorama de la agenda académica de América Latina. Investigaciones, casos y reflexiones. Ciudad Autónoma de Buenos Aires: Ediciones Cooperativas.

Associação Brasileira de Normas Técnicas (ABNT). (2010). NBR ISO 26000. Diretrizes sobre Responsabilidade Social. Rio de Janeiro: ABNT.

Austin, J. E. (2000). The Collaboration Challenge. São Francisco: Jossey Bass.

Benchmarking do Investimento Social Corporativo (BISC). (2015). Relatório 2014. Comunitas. Recuperado de http://www.bisc.org.br/ publicacoerelatorio-2014

Deboni, F. (org.). (2013). Investimento social privado no Brasil: tendências, desafios e potencialidades. Brasília: Instituto Sabin.

Durán, M. E. D. (2013). Aprendiendo de las PYMEs exitosas: análisis de una empresa uruguaya con acciones de responsabilidad social empresarial. Em Em N. Gorrochategui, V. M. Oliveira \& O. D. Licandro (comps.), Responsabilidad social de las organizaciones (RSO): panorama de la agenda académica de América Latina. Investigaciones, casos y reflexiones. Ciudad Autónoma de Buenos Aires: Ediciones Cooperativas.

Fischer, R. M. (1998). Terceiro setor: a meta da autossustentabilidade. Em Senac: Fórum Permanente do Terceiro Setor. $1^{\text {a }}$ Coletânea de Artigos. São Paulo: Senac.

Goldstein, I. (2007). Responsabilidade Social: das grandes corporações ao Terceiro Setor. São Paulo: Ática.

Gorrochategui, N. \& Oliveira, V. M. (2015). Notas sobre Responsabilidad Social Empresarial en América Latina a comienzos del siglo xxi. Em N. Gorrochategui, V. M. Oliveira, J. D. Granda \& Valdivieso, C. (comps.), Responsabilidad Social de las Organizaciones (RSO): avances y propuestas en América Latina. Trujillo, Peru: Universidad Católica Los Ángeles de Chimbote. Recuperado de http://repositorio.uladech.edu.pe/bitstream/ handle/ULADECH_CATÓLICA/83/SIRSO.pdf

Grajew, O. (2015). Instituto Ethos de Responsabilidade Social. Recuperado de www.ethos.org.br 
Grupo de Institutos, Fundações e Empresas (Gife). (2015). Recuperado de http://www.gife.org.br/ogife_investimento_social_privado.asp

Hiernaux, J. P. (1997). O partenariado, uma perspectiva de desenvolvimento do trabalho Social. Em Estivil (org.), O Partenariado Social na Europa: uma estratégia participativa para a inserção (pp. 77-88). Porto: Cadernos REAPN. Recuperado de http://analisesocial.ics.ul.pt/documentos/1218640394P7hUA1qo9Ns32NK9.pdf

Inojosa, R. M. (1999, set./out.). Redes de compromisso social. Revista de Administração Pública (5), 115-141.

Instituto de Pesquisa Econômica Aplicada (Ipea). (2013). Recuperado de http://www.ipea.gov.br/acaosocial/IMG/pdf/doc-28.pdf

Instituto para o Desenvolvimento do Investimento Social (Idis). (2014). Pesquisa World Giving Index 2014. Recuperado de http://idis.org.br/sobre/

Khalil, R. O. (2005). Responsabilidade Social nas microempresas: estudo de caso de microempresas da baixada litorânea e Região dos Lagos do Estado do Rio de Janeiro. Dissertação apresentada ao Mestrado em Sistema de Gestão da Universidade Federal Fluminense. Rio de Janeiro, Brasil. Recuperado de http://www.bdtd.ndc.uff.br/tde_arquivos/14/TDE-200706-04T145357Z-850/Publico/Dissertacao\%20Raja\%20Khalil.pdf

Lariú, A. I. \& Berendson, R. M. (2008). Alianzas entre empresas y organizaciones de sociedade civil. Cátedra "la Caixa" de Responsabilidad Social de la Empresa y Gobierno Corporativo. n. 2, IESE Business School Universidade de Navarra.

Meirino, M. J. (2012). Para Aprofundar. Em V. L. Marques \& C. Alledi Filho (orgs.), Responsabilidade Social: conceitos e práticas (pp. 141-173). São Paulo, Editora Atlas.

Pringle, H. \& Thompson, M. (2000). Marketing social: marketing para causas sociais e a construção de marcas. São Paulo: Makron Books.

Seabra, F. M. (2015). Envolvimento com as partes interessadas a nível interno: a importância dos valores, da liderança e da redefinição dos objetivos da empresa. Em O. L. G. Quelhas et al., Responsabilidade Social Organizacional: modelos, experiências e inovações (pp. 136-143). Rio de Janeiro: Editora Benício Biz.

Serviço Brasileiro de Apoio a Pequenas e Médias Empresas (Sebrae). (2014). Participação das micro e pequenas Empresas na economia brasileira. Brasília: Sebrae. Recuperado de http://www.sebrae.com.br/Sebrae/Portal\%20 
Sebrae/Estudos\%20e\%20Pesquisas/Participacao \%20das\%20micro\%20 e\%20pequenas\%20empresas.pdf

Teodósio, A. S. S. (2009, setembro). Parcerias tri-Setoriais em políticas sociais: em busca de modelos explicativos de sua complexidade na esfera pública. Em XXXIII Encontro Nacional dos Pós-graduados em Administração. São Paulo.

Vives, A. (2011). Prácticas responsables en pequeñas y medianas empresas. Em A. Vives \& E. Peinado-Vara (comps.). La responsabilidad social de la empresa en América Latina. Recuperado de http://www.bibliotecavirtual. info/2012/01/la-responsabilidad-social-de-la-empresa-en-america-latina/

Woods, M. (2014, dez./2015, jan.). Investimento social privado: um olhar para além da doação financeira. Revista $A B C R$, ano I, 1, 24-25. 
